\title{
Patients Have a Right to Safe Surgery
}

\author{
Catherine B. Foss
}

Received: 12 October 2011/ Accepted: 12 October 2011/Published online: 1 November 2011

(C) Springer Science+Business Media, LLC and International Society of Aesthetic Plastic Surgery 2011

The remarkable rise in medical tourism has brought into question the foundation of the patient-doctor relationship and is endangering many who seek low-cost surgery. We see travel agencies brokering surgery for their clients with surgeons they have never met. The patients have no assurance that their surgeon is properly trained or qualified to perform the procedure they will undergo, and all too often, little attention is paid to postsurgical care.

The complication rates for surgeries performed under these circumstances are alarming. An article in the August issue of Aesthetic Surgery Journal entitled Complications from International Surgery Tourism referred to a recent U.S. study showing an increase in postsurgical complication rates among patients returning from surgery overseas. Statistics presented 3 years ago by International Society of Aesthetic Plastic Surgery (ISAPS) member, Professor James Frame (UK), during the Medical Tourism Association meeting in San Francisco reported a 20\% complication rate in patients returning to the UK after surgery abroad. In quite a few cases, the complications were sufficiently serious that the patients had to go directly to a hospital for care on their return.

The Patient Safety Diamond devised by then ISAPS President, Dr. Foad Nahai (US), and presented at the ISAPS Congress in 2010 bases the concept of safe surgery on four factors: the patient, the surgeon, the procedure, and the facility. The patient should be a good candidate for the requested surgery. The surgeon must be properly trained and credentialed. The procedure should be appropriate for the patient. The surgical facility should be an accredited

C. B. Foss ( $\square)$

International Society of Aesthetic Plastic Surgery,

45 Lyme Road, Suite 304, Hanover, NH 03755, USA

e-mail: isaps@conmx.net and proven safe venue with properly trained staff and emergency preparedness.

When the World Health Organization (WHO) introduced the Safe Surgery Saves Lives initiative promoting their Surgical Safety Checklist (www.who.int/patientsafety/safesurgery/en/), ISAPS was one of the initial endorsing organizations at the launch of this program in Washington, DC in June of 2008. A recent study published in the New England Journal of Medicine showed that use of the 19-question checklist reduced surgical complications by more than one third and surgical deaths by almost half in the test hospitals compared with control hospitals. This simple form is used much as a pilot uses a checklist before taking a plane onto a runway for takeoff.

In 2006, Dr. Joao C. Sampaio Goes (Brazil), president of ISAPS at the time, developed key guidelines for those patients who decide to travel for their surgery. These guidelines are posted on the ISAPS website (www.isaps.org ). Several other organizations have since adapted these for their websites. Dr. Jan Poell (Switzerland), the current President of ISAPS, explains the need for this information: "Consumers around the world have looked to ISAPS for over 40 years for the most accurate and reliable information about qualified plastic surgeons and advice about procedures. ISAPS provides a worldwide standard for consumers to reference when traveling for aesthetic plastic surgery."

Many patients have the misconception that anyone with an MD can safely perform any surgical procedure. Legislation around the world is changing to reflect a growing concern that patients are undergoing surgical treatment by incompetent and untrained individuals-sometimes not even physicians. Several countries including Italy, Russia, Mexico, Colombia, the Czech Republic, and Canada are leading the way with new regulations controlling who can perform what specific procedures on which patients and in what facility. This is also the case in Denmark, a front 
runner in strict regulation of all private medical clinics and surgical facilities, indeed closing some that were substandard. Similarly, Germany and France have had strict regulations for many years. Under the auspices of the Comite Européen de Normalisation (CEN), a Europe-wide effort is currently underway to set standards that will protect plastic surgery patients.

A new insurance program developed in the United Kingdom, endorsed by ISAPS and underwritten by Lloyd's of London, the first of its kind in the world, provides revision and complication insurance for plastic surgeons globally to help protect their patients. This insurance is available only if the surgeon is a member of ISAPS. A directory of surgeons already participating in this program is currently available at www.surgeryshield.com. A second insurance product for patients was recently launched in the United Kingdom. Coverage will respond in cases of complications from aesthetic surgery either at home or abroad. This new insurance program requires that patients be screened at home before they travel abroad for surgery to ensure that they are appropriate candidates for the procedure they seek. The intention is that a consultation with a surgeon at home will provide counseling against travel for complicated surgical procedures. The insurance will respond only if surgical complications of surgery by one
ISAPS member surgeon are treated either by that same surgeon or by another ISAPS member surgeon. A patient requiring remedial or corrective treatment once back in his or her country of residence will be directed to an ISAPS surgeon approved to carry out the specific treatment indicated.

The number of patients contacting the ISAPS Executive Office to check on surgeons' credentials shows a growing sophistication among some patients who want assurance that their surgeon is properly trained and competent. The number of cases in which patients suffer at the hands of incompetent doctors or doctors attempting procedures they are not properly trained to perform highlights the need to educate the public about their own surgical safety. Traveling abroad for surgery will continue and can be both justified and rewarding if precautions are taken. But doing so just to save money can lead to poor outcomes, often with avoidable complications, little or no recourse for return to receive additional treatment, and sometimes tragic consequences. The international medical community has a lot of work to do in educating patients to understand that they have the right to ask whether their surgeon is a member of their National Society, board certified (or the equivalent), and trained to perform the specific procedure the patient wants. 